\title{
Amino Acid Interrelationships in Cysteine Toxicity in Neurospora crassa
}

\author{
By P. R. ADIGA, K. SIVARAMA SASTRY AND P. S. SARMA \\ Department of Biochemistry, Indian Institute of Science, Bangalore 12, India
}

(Received 13 December 1961)

\begin{abstract}
SUMMARY
L-Cysteine became toxic to the growth of Neurospora crassa (wild, Em 5297a), in the range 1.0-2.0 $\mathrm{mm}$ in the culture medium. The specificity of cysteine toxicity was shown by absence of toxicity with other sulphydryl compounds ( $\beta$-mercaptoethanol, thioglycollic acid, reduced glutathione) and with cysteine metabolites, L-cysteic acid and taurine, under similar conditions. The toxicity of L-cysteine was completely overcome by supplements of S-methyl-L-cysteine and to a marked extent by DLmethionine and DL-homocysteine; partial counteraction of cysteine toxicity was observed with L-serine, DL-tryptophan, DL-alanine, DL-valine, DL-homoserine or DL-threonine. DL-Methionine and S-methyl-L-cysteine counteracted the inhibitory effect of L-cysteine in two $N$. crassa mutants, namely, methionineless mutant 38706 and cystathionineless mutant 9666.
\end{abstract}

\section{INTRODUCTION}

The existence of complex inter-relationships between amino acids in the growth and nutrition of micro-organisms and animals is well known. In several instances such antagonisms involve amino acids which possess structural similarities or are connected by interlinked metabolic pathways. The toxicity of one amino acid can be annulled by simultaneous supplementation with another, as in the case of the leucine-isoleucine antagonism in rats (Harper, Benton \& Elvehjem, 1955). There are many examples of this kind, but it would appear that these interactions are due to various effects of amino acids on metabolism, some of which are explicable on the basis of mechanisms other than those involving simple structural antagonism. In Neurospora crassa, a reciprocal antagonism between threonine and methionine was shown by Doudney \& Wagner $(1952,1953)$ where the toxicity of one compound was counteracted by the other; it was suggested that threonine interfered with the utilization of homocysteine for the synthesis of methionine. The toxicity of homocysteine for $N$. crassa was overcome by threonine or choline but not by betaine, glycine, serine or methionine (Doudney \& Wagner, 1955). During our earlier work on the effects of sulphur amino acids on molybdenum toxicity in N. crassa (Sivarama Sastry, Ramaiah \& Sarma, 1958), preliminary experiments showed that high concentrations of cysteine were toxic to growth and that methionine could annul this toxicity. These findings indicated that cysteine toxicity was quite different from homocysteine toxicity. Cysteine toxicity has been studied in greater detail and in the present paper it was found that S-methyl-L-cysteine and DL-methionine were good antagonists of L-cysteine and that other amino acids, including DLhomocysteine itself, were partially effective in this respect. 


\section{METHODS}

Organisms. The following Neurospora crassa cultures (obtained through the courtesy of Dr H. K. Mitchell, Division of Biology, California Institute of Technology, Pasadena, California, U.S.A.) were used: N. crassa, wild strain Em 5297a; $N$. crassa, methionineless mutant 38706; $N$. crassa, cystathionineless mutant 9666.

Media. The basal medium used routinely for growing the wild strain was as in earlier studies (Sivarama Sastry, Ramaiah \& Sarma, 1958) and had the following composition (g.): glucose, $20 ; \mathrm{KH}_{2} \mathrm{PO}_{4}, 3 ; \mathrm{NH}_{4} \mathrm{NO}_{3}, 2 ;\left(\mathrm{NH}_{4}\right)_{2} \mathrm{C}_{4} \mathrm{H}_{4} \mathrm{O}_{6}, 1 ; \mathrm{MgSO}_{4}$. $7 \mathrm{H}_{2} \mathrm{O}, 0 \cdot 5 ; \mathrm{NaCl}, 0 \cdot 1$; trace elements $(\mu \mathrm{g}$.): $\mathrm{Zn}, 200 ; \mathrm{Mn}, 200 ; \mathrm{Cu}, 80 ; \mathrm{Fe}, 20$; Mo, 20 ; biotin $5 \mu \mathrm{g}$.; all in 1 l. glass-distilled water.

The methionineless and cystathionineless mutants were grown on this basal medium + DL-methionine $50 \mu \mathrm{g} . / \mathrm{ml}$. Under the conditions of growth used, this concentration of DL-methionine was the minimal concentration for optimal growth.

All chemicals used were of analytical grade.

Amino acids and other compounds. The amino acids used in these experiments were: S-methyl-L-cysteine (Mann Chemicals; DL-homocysteine (Hoffmann La Roche); DL-homoserine (California Foundation for Biochemical Research); DLalanine, DL-glutamic acid, DL-valine (Nutritional Biochemical Corporation, U.S.A.) all others were Merck products.

All the sulphydryl compounds used were added to the required concentrations in the medium as solutions sterilized by Seitz filtration. Other amino acids were incorporated directly in the media which were sterilized by autoclaving at $120^{\circ}$ for $10 \mathrm{~min}$.

Culture technique and estimation of growth. In all experiments the organisms were grown on $10 \mathrm{ml}$. basal medium (adjusted to $\mathrm{pH} 4 \cdot 8-5 \cdot 0$ ) containing all the supplements as described below, in $50 \mathrm{ml}$. Pyrex conical flasks for $72 \mathrm{hr}$. at $30^{\circ} \pm 1^{\circ}$. At the end of incubation the mycelia were harvested, thoroughly washed, dried overnight at $60^{\circ}$ and weighed. All experiments were run in duplicate and repeated at least four times.

\section{RESULTS}

\section{Specificity of L-cysteine toxicity}

L-Cysteine in the medium at concentrations in the range $1 \cdot 0-2 \cdot 0 \mathrm{~mm}$. was toxic to the growth of Neurospora crassa Em 5297a, growth being nearly $80 \%$ inhibited at 2.0 mM. To see whether this was a specific effect or a non-specific one due to an unphysiological concentration of a sulphydryl compound, $\beta$-mercaptoethanol, thioglycollic acid and reduced glutathione were tested; they were completely nontoxic up to $2.0 \mathrm{mM}$. L-Cysteic acid and taurine were also non-inhibitory under similar conditions; thus the toxicity of cysteine was not due to accumulation of these possible products of its metabolism. It would appear that L-cysteine is much more toxic to the growth of these strains of Neurospora crassa than other sulphydryl compounds and its own catabolic end products.

\section{Sulphur amino acid antagonism in cysteine toxicity}

In view of the above observed specificity of cysteine toxicity for Neurospora crassa, the possibility of its antagonism to other sulphur amino acids was explored. In this work, the toxicity of cysteine was studied at $0.5,1.0,1.5$ and $2.0 \mathrm{~mm}$ and 
the annulment of growth inhibition by DL-homocysteine, DL-methionine and S-methyl-L-cysteine was tested at molar ratios of $1: 0 \cdot 5,1: 1$ and $1: 2$. The results are given in Table 1 .

Table 1. Effect of some sulphur amino acids on cysteine toxicity in Neurospora crassa (wild) $\mathrm{Em} 5297$ a

$N$. crassa grown on $10 \mathrm{ml}$. basal medium (pH 4.8-5.0) in $50 \mathrm{ml}$. conical flasks for $72 \mathrm{hr}$. at $30 \pm 1^{\circ}$; with supplements as shown.

\begin{tabular}{|c|c|c|c|c|c|}
\hline \multirow{2}{*}{$\begin{array}{l}\text { Supplements to } \\
\text { basal medium** }\end{array}$} & \multirow[b]{2}{*}{$\begin{array}{c}\text { Cysteine: } \\
\text { amino acid } \\
\text { (molar ratio) }\end{array}$} & \multicolumn{4}{|c|}{ Concentration of cysteine $(\mathrm{mm}) \dagger$} \\
\hline & & $\overparen{0.5}$ & \multicolumn{2}{|c|}{ 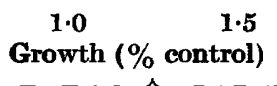 } & $\frac{2 \cdot 0}{19 \cdot 0}$ \\
\hline $\begin{array}{l}\text { None } \\
\text { DL-Methionine }\end{array}$ & $\begin{array}{c}\text { (molar ratio) } \\
\overline{1: 0 \cdot 5} \\
1: 1 \cdot 0 \\
1: 2 \cdot 0\end{array}$ & $\begin{array}{l}75 \cdot 0 \\
80 \cdot 0 \\
87 \cdot 5 \\
90 \cdot 0\end{array}$ & $\begin{array}{l}47 \cdot 0 \\
60 \cdot 0 \\
72 \cdot 5 \\
\mathbf{7 5 \cdot 0}\end{array}$ & $\begin{array}{l}34 \cdot 0 \\
56 \cdot 3 \\
67 \cdot 5 \\
70 \cdot 0\end{array}$ & $\begin{array}{l}19 \cdot 0 \\
48 \cdot 8 \\
58 \cdot 8 \\
68 \cdot 8\end{array}$ \\
\hline S-Methyl-L-cysteine & $\begin{array}{l}1: 1 \cdot 0 \\
1: 2 \cdot 0\end{array}$ & $\begin{array}{l}95 \cdot 5 \\
98 \cdot 0\end{array}$ & $\begin{array}{l}88 \cdot 5 \\
93 \cdot 0\end{array}$ & $\begin{array}{l}87 \cdot 1 \\
92 \cdot 0\end{array}$ & $\begin{array}{l}88 \cdot 5 \\
93 \cdot 0\end{array}$ \\
\hline DL-Homocysteine & $1: 2 \cdot 0$ & - & $75 \cdot 0$ & $60 \cdot 5$ & $60 \cdot 5$ \\
\hline \multicolumn{6}{|c|}{$\begin{array}{l}\text { In all cases, L-cysteine was added to give the ratios indicated. } \\
\text { Values on the basis of growth reached on basal medium alone (mycelial dry weight, 35-40 mg. }\end{array}$} \\
\hline \multicolumn{6}{|c|}{$\begin{array}{l}\text { The growth values recorded in Table } 1 \text { represent the maximal reversals obtained } \\
\text { ith levels of the amino acids found optimal by preliminary trials. The data show } \\
\text { at the three amino acids tested counteract the growth inhibition caused by } \\
\text { steine to a very marked extent throughout its inhibitory range. One of the note- } \\
\text { orthy features brought out by these results is the superiority of S-methyl-L- } \\
\text { steine over methionine and homocysteine. Moreover, judged by the completeness } \\
\text { reversal at the higher level of S-methyl-L-cysteine, and by the constancy of } \\
\text { owth reached at various molar ratios of S-methyl-L-cysteine, it would appear that } \\
\text { ere is a distinct competitive antagonism between these two amino acids. The } \\
\text { versal by homocysteine reveals an interesting antagonism among sulphur amino } \\
\text { ids since homocysteine itself at higher levels becomes toxic. }\end{array}$} \\
\hline
\end{tabular}

\section{Influence of amino acids on cysteine toxicity}

It was of interest to examine whether other amino acids could also counteract cysteine toxicity in Neurospora crassa. Table 2 records the maximal reversals obtained with the amino acids which were found effective in this regard. These data show that cysteine toxicity can be partially counteracted by other amino acids as well and that serine and tryptophan are somewhat more effective than others. It is important to note that the effects of methionine, serine and glycine on cysteine toxicity are quite different from corresponding phenomena in homocysteine toxicity in Neurospora (Doudney \& Wagner, 1955).

Threonine was a good antagonist of homocysteine but not of cysteine. The reverse appeared to hold good with methionine and to a lesser degree with glycine and serine. The data in Tables 1 and 2 taken together suggest, therefore, that the mechanisms by which homocysteine and cysteine become toxic to Neurospora are not identical. Further support for such a conclusion was provided by the absence 
of any effect with choline at a cysteine: choline ratio of even $1: 3$. Other compounds tested and found unable to annul cysteine toxicity were: pyridoxine, $\boldsymbol{p}$-aminobenzoic acid, betaine, folic acid, vitamin $B_{12}$, nicotinic acid.

Table 2. Effect of some amino acids on cysteine toxicity in Neurospora crassa wild type Em 5297 a

Experimental details as in Table 1.

\begin{tabular}{|c|c|c|c|c|}
\hline \multirow{2}{*}{$\begin{array}{l}\text { Supplements to } \\
\text { basal medium* }\end{array}$} & \multirow{2}{*}{$\begin{array}{l}\text { Cysteine: } \\
\text { amino acid } \\
\text { (molar ratio) }\end{array}$} & \multicolumn{3}{|c|}{ Concentration of cysteine $(\mathrm{mm}) \dagger$} \\
\hline & & $1 \cdot 0$ & $\begin{array}{c}1.5 \\
\text { Growth (\% control) }\end{array}$ & $\mathbf{2 \cdot 0}$ \\
\hline None & - & $46 \cdot 1$ & $\mathbf{3 5} \cdot \mathbf{5}$ & $20 \cdot 0$ \\
\hline Glycine & $1: 3$ & $74 \cdot 3$ & $51 \cdot 3$ & $43 \cdot 0$ \\
\hline L-Serine & $1: 3$ & $76 \cdot 3$ & $65 \cdot 8$ & $\mathbf{5 1 \cdot 3}$ \\
\hline DL-Tryptophan & $1: 2$ & $63 \cdot 2$ & $65 \cdot 0$ & $63 \cdot 2$ \\
\hline DL-Alanine & $1: 2$ & $74 \cdot 4$ & $\mathbf{5 8} \cdot \mathbf{1}$ & $40 \cdot 0$ \\
\hline DL-Valine & $1: 2$ & $70 \cdot 0$ & $42 \cdot 0$ & $\mathbf{3 2 \cdot 0}$ \\
\hline DL-Homoserine & $1: 2$ & $74 \cdot 0$ & $58 \cdot 4$ & $47 \cdot 7$ \\
\hline DL-Threonine & $1: 2$ & $70 \cdot 0$ & $62 \cdot 5$ & $45 \cdot 0$ \\
\hline
\end{tabular}

* In all cases, L-cysteine was also included to give the ratios indicated.

$\uparrow$ Values on the basis of growth reached on basal medium alone (mycelial dry weight, $35-40 \mathrm{mg}$.).

\section{Sulphur amino acid antagonisms in Neurospora mutants}

Since the superiority of methionine and S-methyl-L-cysteine over other amino acids in annulling the toxicity of cysteine might be indicative of a specific effect of cysteine on methionine biosynthesis, the sulphur amino acid interrelationships were also studied in two mutants of Neurospora crassa, the methionineless mutant $\mathbf{3 8 7 0 6}$ and the cystathionineless mutant 9666 when both were grown on a basal medium containing the least concentration of methionine which gave optimal growth, as mentioned earlier. The results are presented in Table 3. The results, which represent the maximal degree of antagonism obtained, show the presence of sulphur amino acid antagonisms of a nature similar to those seen with the wild strain. However, cysteine toxicity may not involve only an interference with methionine biosynthesis. With the cystathionineless mutant 9666 both S-methyl-L-cysteine and methionine (particularly the latter) were less efficient in counteracting cysteine toxicity than with the wild strain. Nevertheless, the patterns of growth again indicate the competitive antagonism between S-methyl-1-cysteine and cysteine.

\section{DISCUSSION}

The present work brings out some interesting features of amino acid interrelationships in Neurospora. While general amino acid antagonisms are known, there is no record of any specific amino acid inter-relationships in cysteine toxicity in micro-organisms. The results recorded here, considered with the earlier work of Doudney \& Wagner (1955) about homocysteine toxicity in Neurospora, show that among several sulphydryl compounds, only cysteine and homocysteine exerted toxic effects at comparable concentrations. However, the two toxicities appear to be different, as indicated by the patterns of antagonism obtained with compounds such as choline, methionine and threonine. Since the amino acids that counteract 
cysteine toxicity are those known to be incapable of overcoming homocysteine toxicity, the data suggest that cysteine exerts its toxic effects independently and not by giving rise to abnormal intracellular concentrations of homocysteine, a possibility that would normally be suggested by the known ability of $N$. crassa to perform such a conversion (Horowitz, 1947). Moreover, since cysteic acid and taurine were non-toxic at comparable concentrations, the possibility that the cysteine toxicity was due to such catabolic products appears unlikely.

Table 3. Influence of methionine and $\mathrm{s}-$ methyl-L-cysteine on cysteine toxicity in Neurospora crassa mutants 38706 and 9666

Experimental details as in Table 1, except that the basal medium also contained DL-methionine at $\mathbf{5 0} \mu \mathrm{g} . / \mathrm{ml}$.

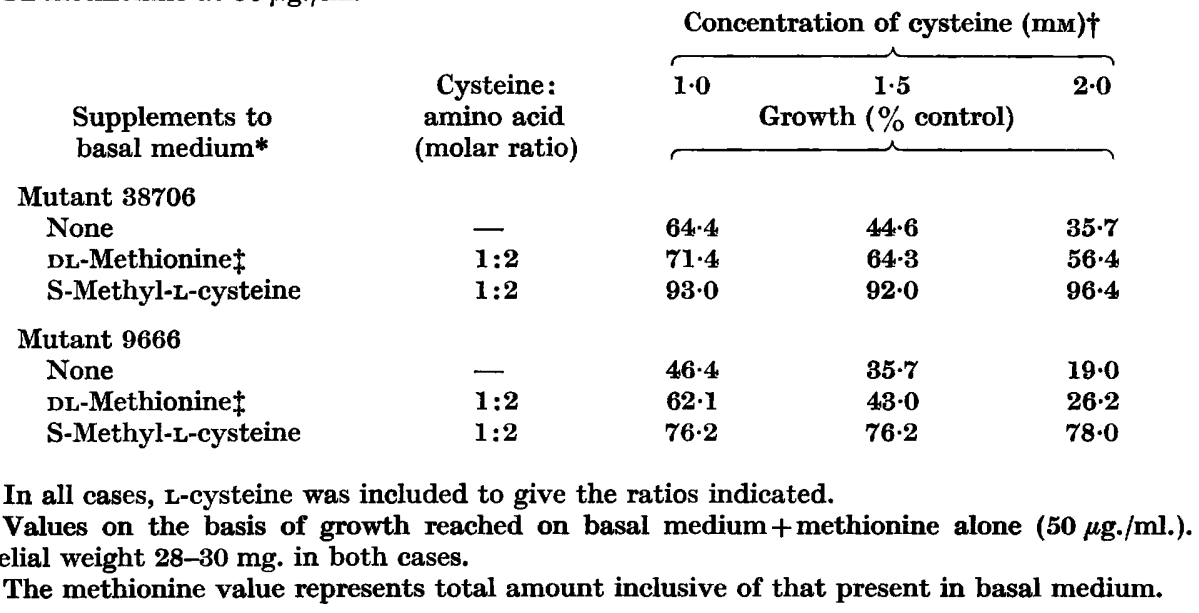

The results in Tables 1 and 3 show that in the examined strains of Neurospora crassa, S-methyl-L-cysteine was a powerful and competitive antagonist of L-cysteine. In view of the reported occurrence of S-methyl-L-cysteine as a normal metabolite in the wild and methionineless strains of $N$. crassa and the capacity of such strains to utilize this compound as a sole sulphur source (Ragland \& Liverman, 1956), the antagonism between cysteine and S-methyl-L-cysteine might be important in the metabolism of sulphur amino acids in Neurospora. Several suggestions have been made in recent years that S-methyl-L-cysteine may itself be incorporated into proteins in Neurospora (Ragland \& Liverman, 1956) and that it might be involved in the formation of methionine by transfer of its thiomethyl group to a four-carbon compound e.g. homoserine (Wiebers \& Garner, 1960) by an alternative pathway not involving cystathionine. Since cysteine itself is a powerful inhibitor of the cystathionine-cleaving enzyme from rat liver (Matsuo \& Greenberg, 1959) it is possible that the annulment of cysteine toxicity by S-methyl-L-cysteine in $N$. crassa may indicate such utilization of S-methyl-L-cysteine for methionine formation under the stress imposed by cysteine toxicity. That homoserine itself did not completely annul cysteine toxicity (Table 2) suggests that synthesis of homoserine may not be totally inhibited and that hence it would be available for the formation of methionine by interaction with S-methyl-L-cysteine by the alternate pathway. 
The counteraction of cysteine toxicity by methionine would appear to be significant, and characteristic of $N$. crassa, since in several pathogenic fungi it has been found incapable of antagonizing the toxic effect of cysteine (Königsbauer, 1951). In Escherichia coli the reverse phenomenon of a specific cysteine counteraction of methionine toxicity was reported by Cimino (1954). The lack of complete counteraction of cysteine toxicity in Neurospora by methionine may be due to the fact that there may be some difference between its effects as exogenous and endogenous methionine (Wiebers \& Garner, 1960). The data about the counteraction of cysteine toxicity by amino acids and the toxicity picture in the mutants here examined (Tables 2, 3) show that cysteine toxicity is a complex phenomenon. It is difficult to envisage a direct antagonism between these amino acids and cysteine, though interaction involving antagonism at the level of absorption of amino acids (O'Barr, Levin \& Reynolds, 1958) has to be considered. However, other explanations are also likely; in this context, the tryptophan $v$. cysteine interaction noted in the present work is interesting since an antagonism between cystine and tryptophan was observed in the rat by Tyner, Lewis \& Eckstein (1950) and in the larvae of the rice moth Corcyra cephalonica St. (Radhakrishna Murthy, Sivarama Sastry \& Sarma, 1957). Another feature is that the amino acids other than tryptophan found significantly effective in the present work are those which have been implicated in methionine formation in $E$. coli or $N$. crassa (Gibson \& Woods, 1960; Kalan \& Ceithaml, 1954; Teas, Horowitz \& Fling, 1948).

We record our thanks to Dr A. N. Radhakrishnan for valuable suggestions. Thanks are also due to the Council of Scientific and Industrial Research, India, for financial assistance.

\section{REFERENCES}

Cimino, S. (1954). Bacterial growth and amino acids. Relation between methionine and cysteine. Bull. Soc. Méd. Chir. catania. 22, 59. (From Chem. Abstr. (1955), 49, 2567.)

DoudNey, C. O. \& WAGNER, R. P. (1952). Threonine inhibition in a strain of Neurospora. Proc. nat. Acad. Sci., Wash. 38, 196.

Doudney, C. O. \& WAGNer, R. P. (1953). A relationship of homocysteine metabolism to thiamine, serine and adenine biosynthesis in a mutant strain of Neurospora. Proc. nat. Acad. Sci., Wash. 39, 1043.

Doudney, C. O. \& Wagner, R. P. (1955). The reversal of homocysteine inhibition of Neurospora by choline and threonine. Arch. Biochem. Biophys. 55, 582.

Gibson, F. \& Woons, D. D. (1960). The synthesis of methionine by suspensions of Escherichia coli. Biochem. J. 74, 160.

Harper, A. E., Benton, D. A. \& Elvehjem, C. A. (1955). L-Leucine, an isoleucine antagonist in the rat. Arch. Biochem. Biophys. 57, 1.

Horowitz, N. H. (1947). Methionine synthesis in Neurospora. The isolation of cystathionine. J. biol. Chem. 171, 255.

Kalan, E. B. \& Ceithaml, J. (1954). Methionine biosynthesis in Escherichia coli. J. Bact. 68, 293.

KönIGSBaUER, H. (1951). Effect of sulphur containing amino acids on the growth of fungi in culture. Mycopathologia (Den Haag), 5, 173 (from Chem. Abstr. (1954), 48, 11,542).

Matsuo, Y. \& Greenberg, D. M. (1959). A crystalline enzyme that cleaves homoserine and cystathionine. III. Coenzyme resolution, activators and inhibitors. J. biol. Chem. 234, 507.

O'Barr, T. P., Levin, H. \& Reynolds, H. (1958). Some interrelationships of amino acids in the nutrition of Leuconostoc mesenteroides. J. Bact. 75, 429. 
Radhakrishna Murthy, R., Sivarama Sastry, K. \& Sarma, P. S. (1957). Role of some B-group vitamins in fat metabolism in rice moth larvae (Corcyra cephalonica $\mathrm{St}$.). J. Sci. Industr. Res. (India), $16 \mathrm{C}, 221$.

Ragland, J. B. \& Liverman, J. L. (1956). s-Methyl-L-cysteine as a naturally occurring metabolite in Neurospora crassa. Arch. Biochem. Biophys. 65, 574.

Sivarama Sastry, K., Ramaiah, A. \& Sarma, P. S. (1958). The influence of molybdenum toxicity on sulphur amino acid metabolism in Neurospora crassa. Biochim. biophys. Acta, 30, 438.

Teas, H. J., Horowitz, N. H. \& Fling, M. (1948). Homoserine as a precursor of threonine and methionine in Neurospora. J. biol. Chem. 172, 651.

Tyner, E. P., Lewis, H. B. \& Eckstern, H. C. (1950). Niacin and the ability of cystine to augment deposition of liver fat. J. biol. Chem. 187, 651 .

Wiebers, J. L. \& Garner, H. R. (1960). Metabolic relationship between cystathionine and methionine in Neurospora. J. Bact. 80, 50. 